\title{
The Effects of Choice on Reading Engagement and Comprehension for Second- and Third-Grade Students: An Action Research Report
}

\author{
Julie P. Fraumeni-McBride \\ St. Catherine University \\ Keywords: literacy, literacy acquisition, reading, reading comprehension, choice, silent reading, aloud reading, \\ Montessori
}

\begin{abstract}
Poor literacy rates contribute to low school performance for children across America. In particular, low-income schools continue to struggle with declining literacy rates. Issues with literacy are often attributed to lack of reading comprehension. This study tested the effects of choice on reading comprehension in second- and third-grade students at a high-income school and a low-income school. Students were observed while reading silently and aloud to see if either method affected reading comprehension. Data were collected from 32 students before, during, and after reading to determine whether students' comprehension levels were higher when given opportunities to choose their own books or when they read assigned books. Trials were performed while students read silently and then aloud. Results indicated that students had higher comprehension levels both when they could choose their own books and when they read silently.
\end{abstract}

Children in the United States usually begin public school in kindergarten at age 5 or 6 . In lowincome areas in Chicago, publicly funded preschool programs are available to families whose income falls at or below the poverty line. Many children from low socioeconomic backgrounds struggle in early childhood education; this struggle is often attributed to difficulty with literacy and reading (Snow, Burns, \& Griffin, 1998; Dearing, Kreider, Simpkins, \& Weiss, 2006). Reading in the first years of early childhood education is often the most important predictor of success in the elementary curriculum (Strickland \& RileyAyers, 2006). If children are unable to read by elementary school, their performance in school is often negatively affected (Entwisle \& Alexander, 1998). Practitioners teach children reading in accordance with the latest research; however, literacy rates remain stagnant (Murnane, Sawhill, \& Snow, 2012). Further research is needed to establish which current methods of reading instruction best improve literacy and to discover additional knowledge that will improve outcomes (Sénéchal \& Young, 2008). This review of the literature focuses on second and third grades. In the present study, children were either given a choice of reading material or assigned a reading. They also were monitored while they read silently or aloud. Choice is presumably an effective component of improving academic outcomes (Iyengar \& Lepper, 2000). Children who are given a choice in reading may develop a sense of ownership and may have higher comprehension rates compared to those assigned a reading. Maria Montessori contended that choice within limits is crucial to a child's enjoyment of and engagement in learning. In Montessori classrooms, children have choice and freedom within limits in all subject areas of the classroom, allowing them to take ownership 
and initiative in their learning (Lillard, 2005). The Montessori education system implements choice as an essential component of children's learning. The current study implies that the Montessori component of choice may also be effective in a non-Montessori setting.

\section{Background}

Poor literacy rates are attributed to various factors such as income level, one of several factors that cannot adequately be addressed by a school's curriculum (Barnett, 1995). The mechanisms that enable a child to read successfully best indicate where a curriculum should focus. Research presents an array of valuable insights dissecting the important components of reading instruction so that children are able to progress toward literacy. Barriers to literacy were outlined by Stanovich (1986). In his seminal review of the literature, he stated that children who read more slowly and with little enjoyment tend to read less frequently than those who read more fluidly and with more enjoyment, resulting in delayed vocabulary development and stunting their ability to read. According to Gardiner (2005), reading is a skill that students must come to enjoy; otherwise, it can impede their overall education. Children's enjoyment of reading affects their reading success through all grade levels and into adulthood. For this reason, it is important to focus on how schools can improve children's reading enjoyment levels in elementary school. This focus could improve literacy acquisition, and more specifically, reading comprehension. This research assessed the effect of choice on children's reading comprehension and enjoyment. In a review of the literature, the author examined studies related to choice, silent reading versus reading aloud, and measurements of reading comprehension.

\section{Choice and Satisfaction}

Several notable studies discuss choice and satisfaction. Iyengar and Lepper (2000) revealed that people are more likely to make a choice when offered six or fewer choices, rather than 24 or 30 . Participants were given a choice of topics for a college essay. One group was given a large number of choices (i.e., 30), while another group was offered a small number of choices (i.e., six). Participants reported greater satisfaction with their selections when their original set of options had been limited. Although this study was conducted using college students, similar results may be found among other age groups. This research supports the idea that a reasonable number of choices improves the likelihood that participants associate enjoyment with their decisions. Choice creates a feeling of ownership; however, limits need to be considered when administering choice for optimal outcomes (Iyengar \& Lepper, 2000).

According to Campbell and Donahue (1997), teachers reported student interest and choice to be factors in test performance. Eighth and twelfth graders who were given a choice in reading more positively perceived those readings. Despite these positive perceptions, statistically significant results were not seen when twelfth-grade students were given a reading comprehension test for the choice reading, while slightly statistically significant negative results were seen among eighth graders. Although these results showed that students did not score better on reading assessments when given the opportunity to choose their books, the findings did show that student perceptions of the assignments were more positive.

A study by Reibstein, Youngblood, and Fromkin (1975) suggested similar results to those found by Iyengar and Lepper (2000). Those who had been given a greater selection expressed higher levels of satisfaction with their choices compared to those with no choice. The study suggests that choice increases perceived freedom, thereby increasing satisfaction with one's choice. Choice is an important factor in individual satisfaction. Student choice in learning enhances determination, ownership, motivation, and involvement (Vitto, 2003).

Lewis, Alessandri, and Sullivan (1990) studied infants aged 2 to 8 months. While monitored, infants moved their arms to control stimuli and then underwent randomized stimuli.. Study results revealed that infants who had control over stimuli were more interested in their environments. Similarly, Deci, Schwartz, 
Sheinman, and Ryan (1981) included observation reports from teachers of fourth- through sixth-grade students. Teachers reported that when students had more autonomy, they were more intrinsically motivated to learn and displayed higher levels of independence and confidence. Students' perceived level of control improved their academic performance.

\section{Reading Silently Versus Aloud}

Studies have shown that favorable results exist in both silent and aloud reading. Wiesendanger and Birlem (1984) revealed that, in nine of 11 research studies of elementary-aged children, students' positive attitude toward reading increased in schools whose curriculum included Sustained Silent Reading (SSR). Takeuchi, Ikeda, and Mizumoto (2012) used imaging techniques to monitor brain activity while subjects read aloud. Results showed that brain activity increased, suggesting a cognitive explanation for the effectiveness of reading aloud. Chow and Chou (2000) found that providing choice in combination with SSR resulted in increased reading comprehension outcomes.

According to Krashen (as cited in Sanden, 2014), silent reading improves the skills needed for comprehension. The study showed that elementary-aged students in SSR programs performed as well as or better in reading comprehension measures than did students in traditional reading comprehension programs. Because the results did not display statistically significant outcomes, more research is needed to determine if the increased comprehension was caused by the SSR program. The National Reading Panel (Hasbrouck, 2006) stated that there is not enough empirical research to support the idea that silent reading results in increased reading comprehension.

The outcomes of studies of both SSR and reading aloud are conflicting or neutral (Hawkins, Hale, Sheeley, \& Ling, 2011; McCallum, Sharp, Bell, \& George, 2004). Because it is not clear which type of reading has a more positive effect on children's reading comprehension, both variables need further study.

\section{Measures of Comprehension}

Reading is an important part of early childhood curriculum and education. The purpose of reading is to create meaning, while the overall goal of literacy is comprehension. According to Burns, Griffin, and Snow (1999), comprehension refers to the understanding of spoken and written language. Language comprehension skills are the foundation of reading comprehension. As early as kindergarten, teachers monitor students' oral language comprehension skills (Storch \& Whitehurst, 2002). It is important to check comprehension both during and after reading to determine if children are developing these skills (Olofsson \& Niedersøe, 1999). Two broad classes of skills are important for later reading performance: code-related skills and oral language skills (Storch \& Whitehurst, 2002; NICHD Early Child Care Research Network [NICHD Early Child Care], 2005; Whitehurst \& Lonigan, 1998). Because preschool children are beginning to learn these skills, it is important for instructors to focus on teaching oral language and comprehension at the beginning stages of reading to supply students with the fundamental skills necessary to achieve appropriate and expected comprehension levels. Oral language skills include "receptive and expressive vocabulary, syntactic and semantic knowledge, and narrative discourse processes such as memory, comprehension and storytelling” (NICHD Early Child Care, 2005, p. 428). The critical skills of oral language are vocabulary and comprehension; for students to develop strong oral language skills, they need to develop proficient comprehension. According to Epstein (2007), as oral language improves, so does reading comprehension. Hohmann (2005) stated, "Comprehension is the process of deriving meaning from action, speech, and text by connecting what you are learning to what you already know.... Children make meaning by assimilating new information into previous understanding” (p. 2). Burns et al. (1999) claimed that comprehension during the preschool years allows children to better understand spoken language and what is read to them; comprehension begins in their everyday conversations as they show understanding of speech through engagement and conversation with their parents, teachers, and peers. To gauge 
comprehension, teachers need to know how to measure it. Comprehension can be measured by monitoring children's reactions to reading materials. As children ask questions and make comments while they read, they should be able to relate information from the book to their own experiences, evidenced in comments made during reading or in responses to the reading (Burns et al., 1999).

\section{Methodology}

This study was conducted at two schools in Chicago: a low-income school and a high-income school. The low-income school's public report showed that $97.4 \%$ of its students came from families that lived below the national poverty level. The high-income school included participants from a private school in which most of the families were categorized in the middle to upper socioeconomic class. While the highincome school's public report does not provide specific information about the incomes of its families, individual tuition costs between $\$ 15,000$ and \$23,000 per year, with limited scholarship availability, making this school available exclusively to students from higher-income households. Thirty-two students participated over a period of 6 weeks. In each school, teachers randomly selected 8- and 9-year-old students for participation: 10 boys and 11 girls from the high-income school and four boys and seven girls from the low-income school. Because many students did not have reliable transportation to school, their attendance was unpredictable. To maintain consistency in the evaluation process, only those with consistent transportation to school were allowed to participate.

The literature review outlined findings that support the major components of this research study. Choice was identified as an important variable that may predict students' enjoyment and increase their reading comprehension (Iyengar \& Lepper, 2000). The researcher of the current study concluded that monitoring children while reading silently and then aloud would help to analyze the impact that reading silently versus aloud has on reading enjoyment (National Institute of Child Health and Human Development, 2000). The current study used four measures to gauge reading comprehension: (a) selfassessment (see Appendix A), (b) researcher observation sheet for questions and comments made by each child throughout reading (see Appendix B), (c) researcher observation scale for recording children's interest during reading (see Appendix C), and (d) reading quiz administered upon completion of the reading (see Appendix D). The four comprehension measures were derived from the previously discussed research to more accurately assess student comprehension of the reading (Burns et al., 1999). Since enjoyment was projected to be the root cause of higher comprehension levels, the variable that instigated this change was choice, which is associated with greater enjoyment and satisfaction (Iyengar \& Lepper, 2000; Reibstein et al., 1975). To eliminate bias, different sample groups read aloud and silently. It was predicted that reading choice would increase reading enjoyment, thereby increasing comprehension. Research suggests that choice is an important factor in reading comprehension, but more information is needed. The current study attempted to discover whether choice positively affects comprehension in second- and third-grade children in high- and low-income schools.

Participants were individually assessed in a quiet room outside of the classroom over the 6-week period. Students were first assigned a grade-appropriate (i.e., second or third grade) reading from the Reading $A-Z$ series, and then were given four evaluations (see Appendices A-D) to measure comprehension. After completing the assigned reading and evaluations, students chose one of three books to read (also from the Reading $A-Z$ series). The same evaluations were conducted after choice reading. For the first three trials, students read both the assigned and chosen readings aloud; in the last three trials of the study, children read assigned and chosen readings silently. Each child participated in one segment of assigned and choice readings per trial. The children completed 12 readings over the course of the study, six assigned and six chosen. In each trial, students first read the assigned reading, followed by evaluation and a quiz measuring comprehension (see Appendices A-D). After completing the assigned segment, students completed the choice segment, in which they were presented with three reading options, followed by evaluation and a quiz measuring comprehension (see Appendices A-D). At the end of each segment, 
students were asked which reading they preferred, assigned or chosen. Because all participants read the assigned reading first, it is possible that maturity explained the improvement seen in reading comprehension or reading preference.

For the assigned readings, children were given books and instructed to read them silently or aloud. They were told they could ask questions or make comments before, during, and after reading. As they read, the researcher used a 10-point scale to evaluate their perceived levels of interest, focus, enjoyment, and comprehension, with 1 being the lowest level and 10 being the highest level (see Appendix C). To gauge students' interest, the researcher observed and coded their facial expressions (e.g., smiling, gasping, or any change in expression). To measure focus, the researcher observed and coded students' reading intensity (e.g., appearance of distraction, looking away from the book, pausing randomly, sluggishness, slouching, or appearance of engagement). To measure enjoyment, the researcher observed and coded students' positive facial expressions while reading. Enjoyment overlapped somewhat with interest, although enjoyment focused on students' overall appearance of relaxation and ease in reading. To measure students' perceived comprehension, the researcher observed and coded gestures, intensity of focus, and appearance of engagement (i.e., Did the reader express enjoyment, focus, and interest?) Participant questions and comments from before, during, and after the readings were recorded on an observation sheet (see Appendix B).

Researcher observations were used to compare researcher perception of child's comprehension levels to actual quiz results that gauged reading comprehension. Researcher observations of perceived focus, enjoyment, interest, and engagement were not definitive measures yet provided insight about signs children may display during reading that can be compared to actual test results. After completing the reading, participants were given a reading comprehension quiz; these quizzes were created by the Reading $A-Z$ series for each reading (see Appendix D). After students took the quiz, they read several statements and were asked to use a 5-point scale to describe how often the statements were true for them, with 1 meaning not at all and 5 meaning all the time (see Appendix A). Afterward, they were asked to choose from among three books, and the same process of evaluating comprehension was repeated. As part of the data collection, after completing the assigned and chosen readings and the assessment, children were asked which reading they preferred. Each child completed this process once per week over a period of 6 weeks (i.e., each child completed one cycle each of assigned and choice trials per week). The following books were used for the readings:

- $\quad$ Trial 1: Healthy Me; Math Test Mix-Up; Winter Vacation; Monsters on Wheels

- $\quad$ Trial 2: Thank You, Everyone!; Caretakers; Carlos and His Teacher; The Mitten

- $\quad$ Trial 3: I’d Like to Be; At the Library; What Has This Tail?; Winter Fun

- Trial 4: I Need an Eraser; Josh Gets Glasses; Stone Soup; A Cold Day

- $\quad$ Trial 5: The Magic Bike; Darby’s Birthday Party; Firefighters; Extreme Insects

- Trial 6: Bats Day and Night; Hugs to Daddy; Spring Is Here; Goats Are Great 
JoMR Fall 2017

Volume 3 (2)
THE EFFECTS OF CHOICE ON READING ENGAGEMENT

Fraumeni-McBride

\section{Analysis of Data}

The data were collected using test scores, researcher observations, self-assessments, and an endof-study survey (see appendices). Comprehension and engagement were based on a six-question quiz, provided by the Reading $A-Z$ series, administered at the end of each reading selection (see Appendix D). Researcher observations, based on perceived student focus, interest, and enjoyment, were recorded before, during, and after reading. The researcher used a 10-point scale to record perceived focus, interest, appearance of comprehension and enjoyment levels for each area, with 1 being the lowest score and 10 being the highest score (see Appendix $\mathrm{C}$ ). The researcher also noted any questions or comments made before, during, and after reading (see Appendix B). Students completed self-assessments after each reading (see Appendix A), rating themselves on a 5-point scale in response to statements about their interest in reading and school, with 1 meaning not at all and 5 meaning all the time. Students also were asked whether they preferred the assigned or chosen reading; their responses were used in conjunction with the other assessments to gauge whether choice had an effect on reading comprehension, meaning that the child's preferred reading may influence comprehension and performance on evaluations. After completing the 6week trials, students were asked questions about reading. These questions pertained to their interest in reading silently or aloud and to the factors that help them to read at home, such as parent encouragement or number of books at home.

Comparisons between the significance of the regression coefficients of the dummy code treatment condition were made. Figure 1 and Table 1 compare average responses for students who chose their books and for those who were assigned a reading. Similarly, Figure 2 and Table 2 compare the average responses for students who read aloud and those who read silently. These tests were performed using regression analysis, displaying a 95\% confidence interval (CI). Figure 3 and Table 3 compare average responses for students who preferred or did not prefer the reading. Figure 4 provides an overview of the effect on test scores of chosen versus assigned reading, aloud versus silent reading, and preferred versus not-preferred reading.

\section{Conclusions and Implications for Future Research}

This study's data show that children who were given a choice in reading scored higher in reading comprehension than when they were assigned a reading; likewise, children who read silently scored higher on comprehension measures than when they read aloud. Previous studies showed neutral results in testing the variability between reading silently versus aloud (Hawkins et al., 2011; McCallum et al., 2004); however, this study's findings also suggest that silent reading is optimal (Sanden, 2014). Data collected from students from both high- and low-income schools were used, and the results regarding the effects of choice and silent reading on reading comprehension were the same. As corroborated by other studies (Deci et al., 1981; Iyengar \& Lepper, 2000; Lewis et al., 1990; Reibstein et al., 1975), this study demonstrates that choice positively affects learning. Current practices in school literacy programs focus on assigned readings and often require children to read aloud. This study indicates that choice and silent reading are significant factors in improving reading comprehension scores. Because a major component of early elementary education is reading comprehension, children should be given the opportunity to enjoy reading and take ownership of their own learning. These goals can be accomplished by offering students a limited variety of reading options and by providing time to read independently. Future research is needed on direct practices that may improve phonics instruction and other mechanical aspects of literacy; however, results strongly indicate that comprehension is greatly influenced by choice and by opportunities to read silently.

While this study presents broad implications, limitations include research design (i.e., small sample size, specific location); further research with larger sample sizes in different geographical areas may strengthen findings. Various components of reading comprehension that are important for literacy acquisition need to be considered, including formal assessments that measure comprehension within the context of choice (Pressley, Mohan, Raphael, \& Fingeret, 2007). 


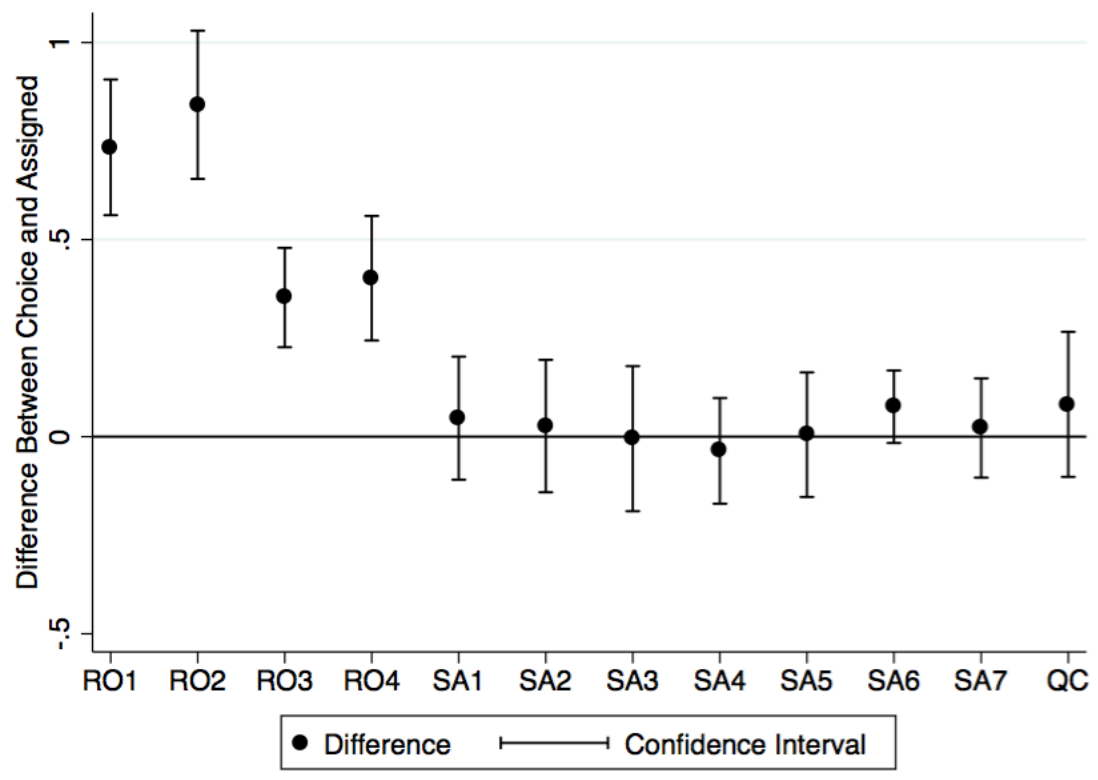

Figure 1. Difference in means between chosen and assigned readings. The $x$-axis shows the variables of interest. The $y$-axis shows the difference on each measure between chosen and assigned readings. The points on the graph plot the differences in means between chosen readings and assigned readings for each of the variables. The differences in means between chosen and assigned readings for RO1, RO2, RO3, and RO4 are statistically significant. For SA1, the difference is not statistically significant. RO1 = researcher observation of child's interest level, 95\% CI [0.56, 0.91]; RO2 = researcher observation of child's enjoyment level, 95\% CI [0.65, 1.03]; RO3 = researcher observation of child's comprehension level, 95\% CI [0.23, 0.48]; RO4 = researcher observation of child's focus during reading, 95\% CI [0.24, 0.56]; SA1 = child self-assessment (I enjoy reading), 95\% CI [-0.11, 0.20]; SA2 = child self-assessment (I enjoy reading aloud), 95\% CI [-0.14, 0.20]; SA3 = child self-assessment (I enjoy reading silently), 95\% CI [-0.19, 0.18]; SA4 = child self-assessment (It's hard for me to understand what is going on when I read), 95\% CI [-0.17, 0.10]; SA5: child self-assessment (I am interested in the books that I am assigned to read), 95\% CI [-0.15, 0.16]; SA6 = child self-assessment (I can read well), 95\% CI [-0.02, 0.17]; SA7 = child self-assessment (I enjoy going to school), 95\% CI [-0.10, 0.15]; QC = number of questions or comments student made before, during, or after reading, 95\% CI [-0.10, 0.27]. RO1, RO2, RO3, and RO4 are scored on a 10-point Likert scale ranging from 1 (not at all) to 10 (all the time). SA1, SA2, SA3, SA4, SA5, SA6, and SA7 are scored on a 5-point Likert scale ranging from 1 (not at all) to 5 (all the time). $p<.05$ for $\mathrm{RO} 1, \mathrm{RO} 2, \mathrm{RO} 3$, and $\mathrm{RO} 4$. The remaining variables are not statistically significant. 
JoMR Fall 2017

THE EFFECTS OF CHOICE ON READING ENGAGEMENT

Volume 3 (2)

Fraumeni-McBride

Table 1

Effects of Chosen vs. Assigned Reading for Students

\begin{tabular}{|c|c|c|c|c|}
\hline \multirow[b]{2}{*}{ Variable } & \multicolumn{2}{|c|}{ Reading type } & \multirow[b]{2}{*}{ Difference } & \multirow[b]{2}{*}{$p^{*}$} \\
\hline & Chosen $(M)$ & Assigned $(M)$ & & \\
\hline Test score & 90.386 & 86.060 & 4.326 & .009 \\
\hline RO1 & 7.739 & 7.005 & 0.734 & .000 \\
\hline RO2 & 7.489 & 6.647 & 0.842 & .000 \\
\hline RO3 & 8.283 & 7.929 & 0.353 & .000 \\
\hline RO4 & 8.543 & 8.141 & 0.402 & .000 \\
\hline SA1 & 4.506 & 4.459 & 0.047 & .553 \\
\hline SA2 & 3.250 & 3.223 & 0.027 & .747 \\
\hline SA3 & 4.239 & 4.245 & -0.005 & .953 \\
\hline SA4 & 2.276 & 2.312 & -0.036 & .601 \\
\hline SA5 & 3.897 & 3.891 & 0.005 & .946 \\
\hline SA6 & 4.647 & 4.571 & 0.076 & .109 \\
\hline SA7 & 4.234 & 4.212 & 0.022 & .733 \\
\hline QC & 0.228 & 0.147 & 0.082 & .381 \\
\hline $\begin{array}{l}\text { Number of } \\
\text { observations }\end{array}$ & 184 & 184 & & \\
\hline
\end{tabular}

Note. RO1 = researcher observation of child's interest level; RO2 = researcher observation of child's enjoyment level; RO3 = researcher observation of child's comprehension level; RO4 = researcher observation of child's focus during reading; SA1 = child self-assessment (I enjoy reading); SA2 = child self-assessment (I enjoy reading aloud); SA3 = child self-assessment (I enjoy reading silently); SA4 = child self-assessment (It's hard for me to understand what is going on when I read); SA5: child self-assessment (I am interested in the books that I am assigned to read); SA6 = child self-assessment (I can read well); SA7 = child self-assessment (I enjoy going to school); QC = number of questions or comments student made before, during, or after reading. RO1, RO2, RO3, and RO4 are scored on a 10point Likert scale ranging from 1 (not at all) to 10 (all the time). SA1, SA2, SA3, SA4, SA5, SA6, and SA7 are scored on a 5 -point Likert scale ranging from 1 (not at all) to 5 (all the time).

${ }^{*} p<.05$ 


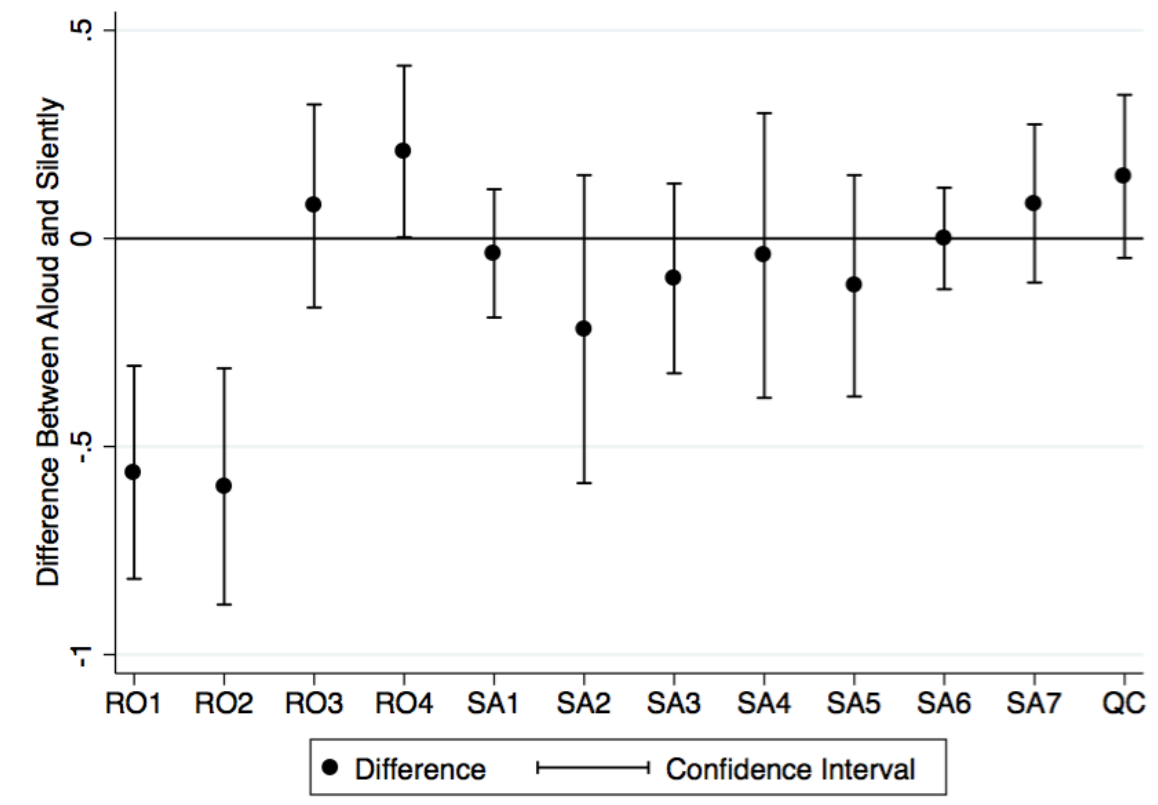

Figure 2. Difference in mean scores between students reading aloud and silently. The $x$-axis shows the variables of interest. The $y$-axis shows the difference in means on each measure between students reading aloud and reading silently. Therefore, the differences in means between reading aloud and silently for RO1, RO2, and RO4 are statistically significant. For RO3 and SA1 through QC, the difference is not statistically significant. RO1 = researcher observation of child's interest level, 95\% CI [-0.82, -0.31]; RO2 = researcher observation of child's enjoyment level, 95\% CI [-0.88, -0.31]; RO3 = researcher observation of child's comprehension level, 95\% CI [-0.17, 0.32]; RO4 = researcher observation of child's focus during reading, 95\% CI [0.00, 0.42]; SA1 = child self-assessment (I enjoy reading), 95\% CI [-0.19, 0.12]; SA2 = child self-assessment (I enjoy reading aloud), 95\% CI [-0.59, 0.15]; SA3 = child self-assessment (I enjoy reading silently), 95\% CI [-0.32, 0.13]; SA4 = child self-assessment (It's hard for me to understand what is going on when I read), 95\% CI [-0.38, 0.30]; SA5: child self-assessment (I am interested in the books that I am assigned to read), 95\% CI [-0.38, 0.15]; SA6 = child self-assessment (I can read well), 95\% CI [-0.12, 0.12]; SA7 = child self-assessment (I enjoy going to school), 95\% CI [-0.11, 0.27]; QC = number of questions or comments student made before, during, or after reading, 95\% CI [-0.05, 0.35]. RO1, RO2, RO3, and RO4 are scored on a 10-point Likert scale ranging from 1 (not at all) to 10 (all the time). SA1, SA2, SA3, SA4, SA5, SA6, and SA7 are scored on a 5-point Likert scale ranging from 1 (not at all) to 5 (all the time). $p<.05$ for RO1, RO2, and RO4. The remaining variables are not statistically significant. 
JoMR Fall 2017

THE EFFECTS OF CHOICE ON READING ENGAGEMENT

Volume 3 (2)

Fraumeni-McBride

Table 2

Effects of Silent vs. Aloud Reading for Students

\begin{tabular}{|c|c|c|c|c|}
\hline \multirow[b]{2}{*}{ Variable } & \multicolumn{2}{|c|}{ Reading type } & \multirow[b]{2}{*}{ Difference } & \multirow[b]{2}{*}{$p^{*}$} \\
\hline & Aloud $(M)$ & Silent $(M)$ & & \\
\hline Test score & 88.490 & 87.955 & 0.535 & .685 \\
\hline RO1 & 7.091 & 7.653 & -0.562 & .000 \\
\hline RO2 & 6.770 & 7.366 & -0.596 & .000 \\
\hline RO3 & 8.145 & 8.067 & 0.078 & .528 \\
\hline RO4 & 8.447 & 8.238 & 0.209 & .050 \\
\hline SA1 & 4.464 & 4.500 & -0.036 & .644 \\
\hline SA2 & 3.127 & 3.345 & -0.218 & .249 \\
\hline SA3 & 4.194 & 4.290 & -0.096 & .406 \\
\hline SA4 & 2.274 & 2.315 & -0.041 & .811 \\
\hline SA5 & 3.837 & 3.951 & -0.114 & .396 \\
\hline SA6 & 4.609 & 4.609 & 0.000 & 1.000 \\
\hline SA7 & 4.265 & 4.181 & 0.084 & .387 \\
\hline QC & 0.262 & 0.113 & 0.149 & .140 \\
\hline $\begin{array}{l}\text { Number of } \\
\text { observations }\end{array}$ & 184 & 184 & & \\
\hline
\end{tabular}

Note. RO1 = researcher observation of child's interest level; RO2 = researcher observation of child's enjoyment level; RO3 = researcher observation of child's comprehension level; RO4 = researcher observation of child's focus during reading; SA1 = child self-assessment $($ I enjoy reading); SA2 = child self-assessment (I enjoy reading aloud); SA3 = child self-assessment (I enjoy reading silently); SA4 = child self-assessment (It's hard for me to understand what is going on when I read); SA5: child self-assessment (I am interested in the books that I am assigned to read); SA6 = child self-assessment (I can read well); SA7 = child self-assessment (I enjoy going to school); QC = number of questions or comments student made before, during, or after reading. RO1, RO2, RO3, and RO4 are scored on a 10point Likert scale ranging from 1 (not at all) to 10 (all the time). SA1, SA2, SA3, SA4, SA5, SA6, and SA7 are scored on a 5-point Likert scale ranging from 1 (not at all) to 5 (all the time).

${ }^{*} p<.05$ 


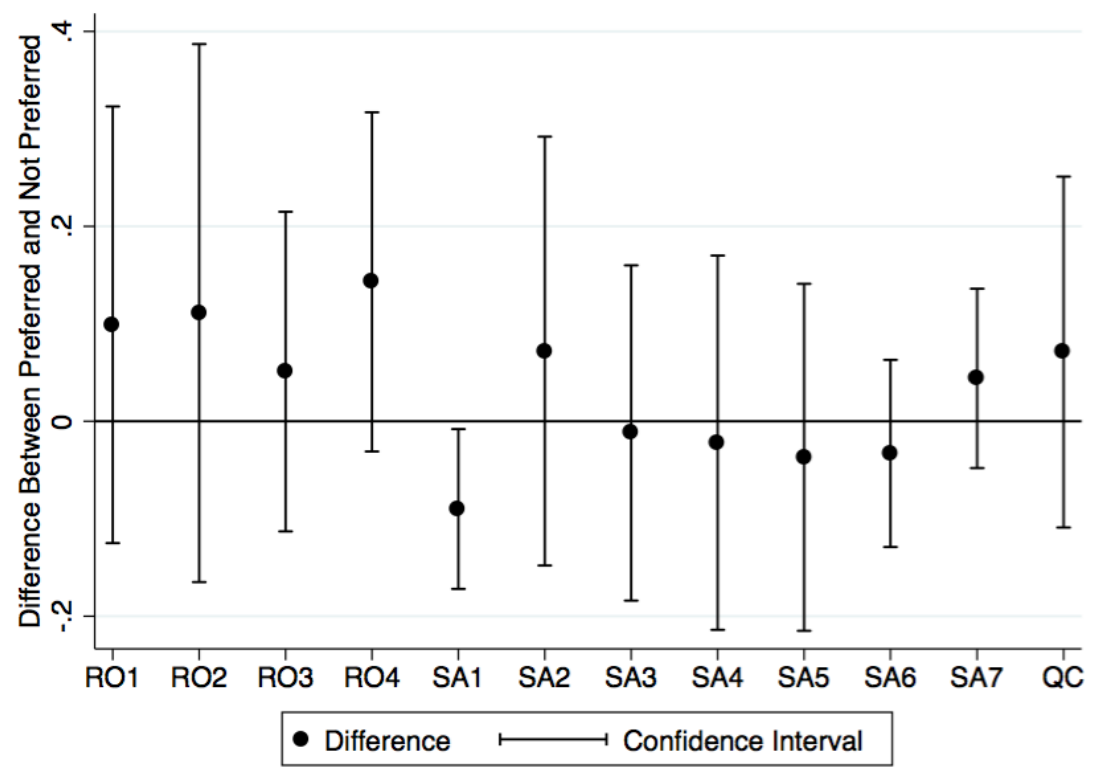

Figure 3. Difference in means between preferred and not-preferred readings. RO1 = researcher observation of child's interest level, 95\% CI [-0.13, 0.32]; RO2 = researcher observation of child's enjoyment level, 95\% CI [-0.17, 0.39]; RO3 = researcher observation of child's comprehension level, 95\% CI [-0.11, 0.22]; RO4 = researcher observation of child's focus during reading, 95\% CI [-0.03, 0.32]; SA1 = child self-assessment (I enjoy reading), 95\% CI [-0.17, -0.01]; SA2 = child self-assessment (I enjoy reading aloud), 95\% CI [-0.15, 0.29]; SA3 = child self-assessment (I enjoy reading silently), 95\% CI [-0.18, 0.16]; SA4 = child self-assessment (It's hard for me to understand what is going on when I read), 95\% CI [-0.21, 0.17]; SA5: child self-assessment (I am interested in the books that I am assigned to read), 95\% CI [-0.22, 0.14]; SA6 = child self-assessment (I can read well), 95\% CI [-0.13, 0.06]; SA7 = child self-assessment (I enjoy going to school), 95\% CI [-0.05, 0.14]; QC = number of questions or comments student made before, during, or after reading, 95\% CI [-0.11, 0.25]. RO1, RO2, RO3, and RO4 are scored on a 10-point Likert scale ranging from 1 (not at all) to 10 (all the time). SA1, SA2, SA3, SA4, SA5, SA6, and SA7 are scored on a 5point Likert scale ranging from 1 (not at all) to 5 (all the time). $p<.05$ for SA1. The remaining variables are not statistically significant. 
JoMR Fall 2017

Volume 3 (2)
THE EFFECTS OF CHOICE ON READING ENGAGEMENT

Fraumeni-McBride

Table 3

Effect of Student Preferences

\begin{tabular}{|c|c|c|c|c|}
\hline \multirow[b]{2}{*}{ Variable } & \multicolumn{2}{|c|}{ Reading type } & \multirow[b]{2}{*}{ Difference } & \multirow[b]{2}{*}{$p^{*}$} \\
\hline & Preferred $(M)$ & Not preferred $(M)$ & & \\
\hline Test score & 88.766 & 87.685 & 1.081 & .429 \\
\hline RO1 & 7.422 & 7.323 & 0.099 & .386 \\
\hline RO2 & 7.124 & 7.013 & 0.111 & .430 \\
\hline RO3 & 8.132 & 8.081 & 0.051 & .538 \\
\hline RO4 & 8.414 & 8.271 & 0.143 & .109 \\
\hline SA1 & 4.437 & 4.527 & -0.090 & .035 \\
\hline SA2 & 3.272 & 3.201 & 0.072 & .520 \\
\hline SA3 & 4.236 & 4.248 & -0.012 & .891 \\
\hline SA4 & 2.283 & 2.305 & -0.022 & .820 \\
\hline SA5 & 3.875 & 3.913 & -0.037 & -.678 \\
\hline SA6 & 4.592 & 4.625 & -0.033 & .497 \\
\hline SA7 & 4.245 & 4.201 & 0.044 & .348 \\
\hline QC & 0.223 & 0.152 & 0.071 & .437 \\
\hline $\begin{array}{l}\text { Number of } \\
\text { observations }\end{array}$ & 183 & 185 & & \\
\hline
\end{tabular}

Note. RO1 = researcher observation of child's interest level; RO2 = researcher observation of child's enjoyment level; RO3 = researcher observation of child's comprehension level; RO4 = researcher observation of child's focus during reading; SA1 = child self-assessment (I enjoy reading); SA2 = child self-assessment (I enjoy reading aloud); SA3 = child self-assessment (I enjoy reading silently); SA4 = child self-assessment (It's hard for me to understand what is going on when I read); SA5: child self-assessment (I am interested in the books that I am assigned to read); SA6 = child self-assessment (I can read well); SA7 = child self-assessment (I enjoy going to school); QC = number of questions or comments student made before, during, or after reading. RO1, RO2, RO3, and RO4 are scored on a 10point Likert scale ranging from 1 (not at all) to 10 (all the time). SA1, SA2, SA3, SA4, SA5, SA6, and SA7 are scored on a 5-point Likert scale ranging from 1 (not at all) to 5 (all the time).

${ }^{*} p<.05$ 
JoMR Fall 2017

Volume 3 (2)
THE EFFECTS OF CHOICE ON READING ENGAGEMENT

Fraumeni-McBride

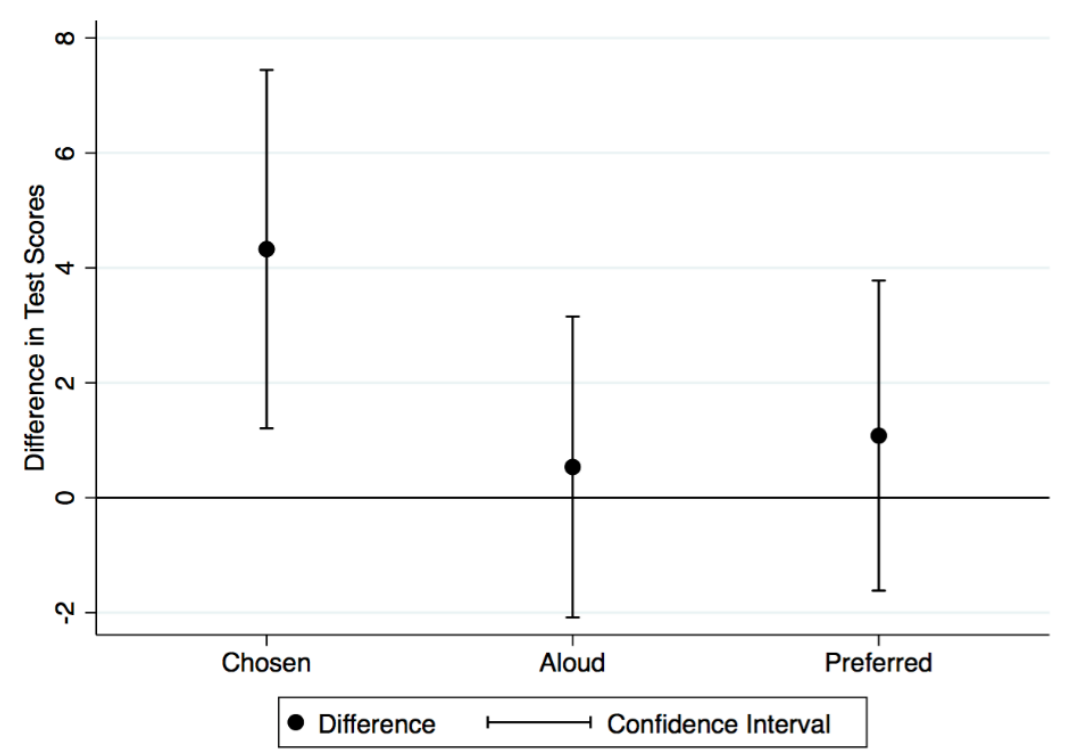

Figure 4. Effect on test scores (\%) of chosen versus assigned, aloud versus silent, and preferred versus not-preferred readings. 95\% CIs [1.21, 7.44], [-2.08, 3.15], [-1.62, 3.78], respectively.

\section{AUTHOR INFORMATION}

Julie Fraumeni-McBride is a doctoral student in education and disability studies at Chapman University. She can be reached at juliepmcbride@gmail.com.

\section{References}

Barnett, W. (1995). Long-term effects of early childhood programs on cognitive and school outcomes. The Future of Children, 5(3), 25-50. https://doi.org/10.2307/1602366

Burns, S. M., Griffin, P., \& Snow, C. E. (Eds.). (1999). Starting out right: A guide to promoting children's reading success. Washington, DC: National Academy Press.

Campbell, J. R., \& Donahue, P. L. (1997). Students selecting stories: The effects of choice in reading assessment. U.S. Department of Education, National Center for Education Statistics, NCES 97491. Retrieved from https://nces.ed.gov/nationsreportcard/pdf/main1994/97491.pdf

Chow, P.-H., \& Chou, C.-T. (2000). Evaluating sustained silent reading in reading classes. The Internet TESL Journal, 6(11). Retrieved from http://iteslj.org/Articles/Chow-SSR.html

Dearing, E., Kreider, H., Simpkins, S., \& Weiss, H. B. (2006). Family involvement in school and lowincome children's literacy: Longitudinal associations between and within families. Journal of Educational Psychology, 98, 653-654. https://doi.org/10.1037/0022-0663.98.4.653

Deci, E. L., Schwartz, A. J., Sheinman, L., \& Ryan, R. M. (1981). An instrument to assess adults' orientations toward control versus autonomy with children: Reflections on intrinsic motivation and perceived competence. Journal of Educational Psychology, 73, 642-650. http://dx.doi.org/10.1037/0022-0663.73.5.642

Entwisle, D. R., \& Alexander, K. L. (1998). Facilitating the transition to first grade: The nature of transition and research on factors affecting it. The Elementary School Journal, 98, 351-364. https://doi.org/10.1086/461901

Epstein, A. S. (2007). The intentional teacher: Choosing the best strategies for young children's learning. Washington, DC: National Association for the Education of Young Children. 
Gardiner, S. (2005). Building student literacy through sustained silent reading. Alexandria, VA: Association for Supervision and Curriculum Development.

Hasbrouck, J. (2006). For students who are not yet fluent, silent reading is not the best use of classroom time. American Educator, 30(2). Retrieved from http://www.readingrockets.org/article/studentswho-are-not-yet-fluent-silent-reading-not-best-use-classroom-time

Hawkins, R. O., Hale, A., Sheeley, W., \& Ling, S. (2011). Repeated reading and vocabulary-previewing interventions to improve fluency and comprehension for struggling high-school readers. Psychology in the Schools, 48, 59-77. https://doi.org/10.1002/pits.20545

Hohmann, M. (2005). Growing Readers early literacy curriculum: Teacher guide. Ypsilanti, MI: HighScope Educational Research Foundation Press.

Iyengar, S. S., \& Lepper, M. R. (2000). When choice is demotivating: Can one desire too much of a good thing? Journal of Personality and Social Psychology, 79, 995-1006. https://doi.org/10.1037/00223514.79.6.995

Lewis, M., Alessandri, S. M., \& Sullivan, M. W. (1990). Violation of expectancy, loss of control, and anger expressions in young infants. Developmental Psychology, 26, 745-751. https://doi.org/10.1037/0012-1649.26.5.745

Lillard, A. S. (2005). Montessori: The science behind the genius. New York, NY: Oxford University Press.

McCallum, R. S., Sharp, S., Bell, S. M., \& George, T. (2004). Silent versus oral reading comprehension and efficiency. Psychology in the Schools, 41, 241-246. https://doi.org/10.1002/pits.10152

Murnane, R., Sawhill, I., \& Snow, C. (2012). Literacy challenges for the twenty-first century: Introducing the issue. The Future of Children, 22(2), 3-15. https://doi.org/10.1353/foc.2012.0013

National Institute of Child Health and Human Development. (2000). Report of the National Reading Panel. Teaching children to read: An evidence-based assessment of the scientific research literature on reading and its implications for reading instruction. Retrieved from https://www.nichd.nih.gov/publications/pubs/nrp/pages/smallbook.aspx

NICHD Early Child Care Research Network. (2005). Pathways to reading: The role of oral language in the transition to reading. Developmental Psychology, 41, 428-442. https://doi.org/10.1037/00121649.41.2.428

Olofsson, A., \& Niedersøe, J. (1999). Early language development and kindergarten phonological awareness as predictors of reading problems: From 3 to 11 years of age. Journal of Learning Disabilities, 32(5), 464-472. https://doi.org/10.1177/002221949903200512

Pressley, M., Mohan, L., Raphael, L. M., \& Fingeret, L. (2007). How does Bennett Woods Elementary School produce such high reading and writing achievement? Journal of Educational Psychology, 99, 221-240. Retrieved from https://doi.org/10.1037/0022-0663.99.2.221

Reibstein, D. J., Youngblood, S. A., \& Fromkin, H. L. (1975). Number of choices and perceived decision freedom as a determinant of satisfaction and consumer behavior. The Journal of Applied Psychology, 60, 434-437. https://doi.org/10.1037/h0076906

Sanden, S. (2014). Out of the shadows of SSR: Real teachers' classroom independent reading practices. Language Arts, 91, 161-175.

Sénéchal, M., \& Young, L. (2008). The effect of family literacy interventions on children's acquisition of reading from kindergarten to grade 3: A meta-analytic review. Review of Educational Research, 78, 880-907. https://doi.org/10.3102/0034654308320319

Snow, C. E., Burns, M. S., \& Griffin, P. (Eds.). (1998). Preventing reading difficulties in young children. Washington, DC: National Academy Press.

Stanovich, K. E. (1986). Matthew effects in reading: Some consequences in individual differences in the acquisition of literacy. Reading Research Quarterly, 21, 360-407. https://doi.org/10.1598/RRQ.21.4.1 
Storch, S. A., \& Whitehurst, G. J. (2002). Oral language and code-related precursors to reading: Evidence from a longitudinal structural model. Developmental Psychology, 38, 934-947. https://doi.org/10.1037/0012-1649.38.6.934

Strickland, D. S., \& Riley-Ayers, S. (2006). Early literacy: Policy and practice in the preschool years. National Institute for Early Education Research, Policy Brief. Retrieved from http://nieerwww1.rutgers.edu/resources/policybriefs/10.pdf

Takeuchi, O., Ikeda, M., \& Mizumoto, A. (2012). Reading aloud activity in L2 and cerebral activation. RELC Journal: A Journal Of. Language Teaching Research, 43, 151-167.

Vitto, J. (2003). Relationship-driven classroom management. Thousand Oaks, CA: Corwin Press, Inc.

Whitehurst, G. J., \& Lonigan, C. J. (1998). Child development and emergent literacy. Child Development, 69, 848-872. https://doi.org/10.1111/j.1467-8624.1998.tb06247.x

Wiesendanger, K. D., \& Birlem, E. D. (1984). The effectiveness of SSR: An overview of the research. Reading Horizons, 24(3). Retrieved from

http://scholarworks.wmich.edu/reading_horizons/vol24/iss3/9 
JoMR Fall 2017

Volume 3 (2)
THE EFFECTS OF CHOICE ON READING ENGAGEMENT

Fraumeni-McBride

Appendix A:

Enjoyment of reading self-assessment

Students, please complete this assessment discussing your enjoyment of reading. Please make sure to answer each question by circling your choice from the scale. Please be honestanswers will not affect your grade in any way.

Participant:

Not at all $\mid$ A little $\mid$ Some of the time $\mid$ Most of the time $\mid$ All the time

\begin{tabular}{|c|c|}
\hline I enjoy reading. & 12345 \\
\hline I enjoy reading aloud. & 12345 \\
\hline I enjoy reading silently. & 12345 \\
\hline $\begin{array}{l}\text { It's hard for me to understand what is going } \\
\text { on when I read. }\end{array}$ & 12345 \\
\hline $\begin{array}{l}\text { I am interested in the books that I am } \\
\text { assigned to read. }\end{array}$ & 123345 \\
\hline I can read well. & 12345 \\
\hline I enjoy going to school. & 12345 \\
\hline
\end{tabular}


JoMR Fall 2017

Volume 3 (2)
THE EFFECTS OF CHOICE ON READING ENGAGEMENT

Fraumeni-McBride

Appendix B:

Questions and comments made by child while reading

Book choices presented:

Book selection:

Participant:

Silent Reading

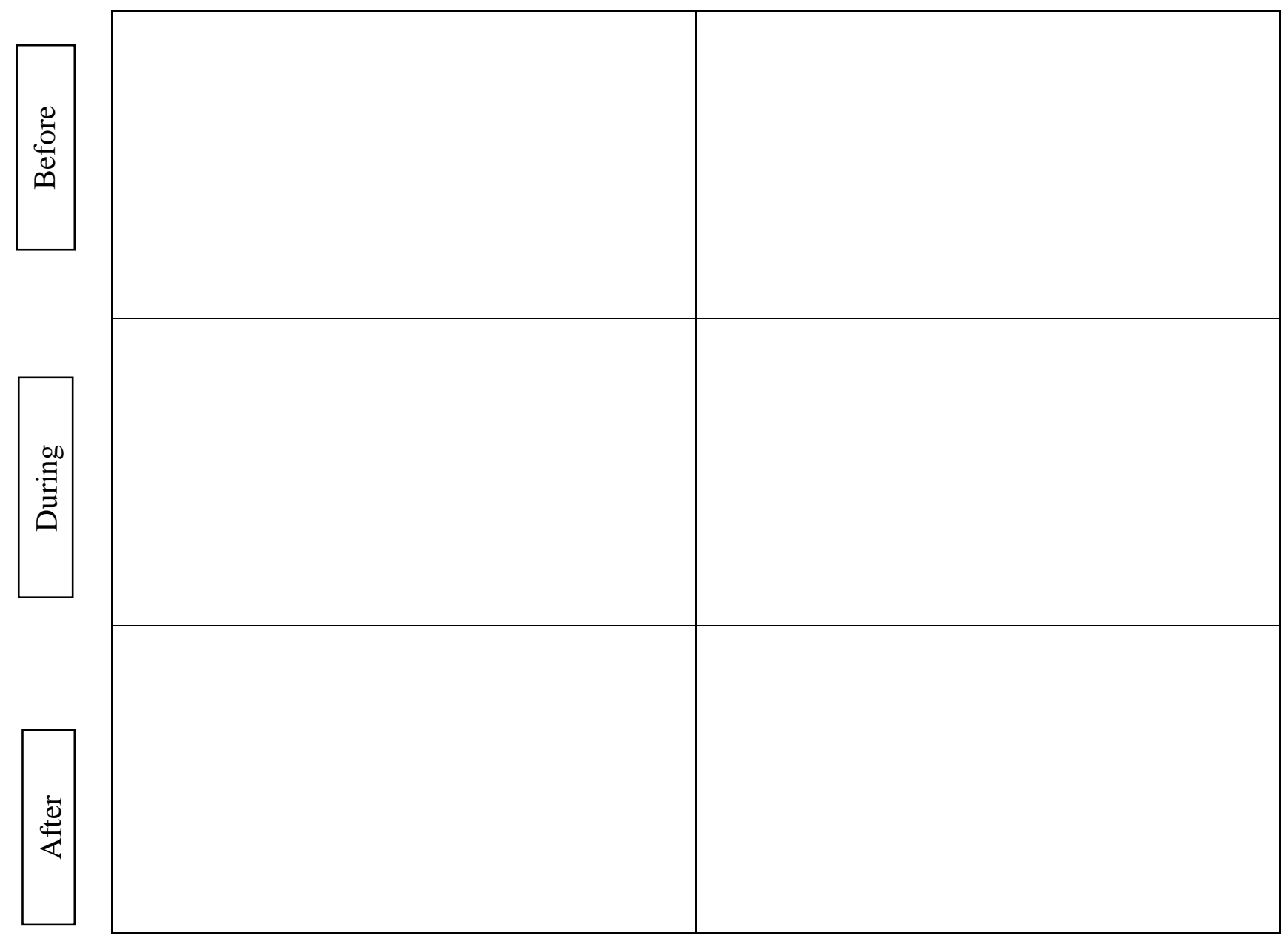

Reading Aloud

Researcher comments: 
JoMR Fall 2017

Volume 3 (2)
THE EFFECTS OF CHOICE ON READING ENGAGEMENT

Fraumeni-McBride

Appendix C:

Researcher observation/journal of child's interest level during reading session

Participant:

Silent Reading

\begin{tabular}{|c|c|}
\hline $\begin{array}{l}\text { Child's interest level } \\
\qquad \begin{array}{llllllllll}1 & 2 & 3 & 4 & 5 & 6 & 7 & 8 & 9 & 10\end{array}\end{array}$ & $\begin{array}{l}\text { Child's interest level } \\
\qquad \begin{array}{llllllllll}1 & 2 & 3 & 4 & 5 & 6 & 7 & 8 & 9 & 10\end{array}\end{array}$ \\
\hline $\begin{array}{l}\text { Child's enjoyment level } \\
\qquad \begin{array}{llllllllll}1 & 2 & 3 & 4 & 5 & 6 & 7 & 8 & 9 & 10\end{array}\end{array}$ & $\begin{array}{l}\text { Child's enjoyment level } \\
\qquad \begin{array}{llllllllll}1 & 2 & 3 & 4 & 5 & 6 & 7 & 8 & 9 & 10\end{array}\end{array}$ \\
\hline $\begin{array}{l}\text { Perception of child's comprehension level } \\
\qquad \begin{array}{llllllllll}1 & 2 & 3 & 4 & 5 & 6 & 7 & 8 & 9 & 10\end{array}\end{array}$ & $\begin{array}{l}\text { Perception of child's comprehension level } \\
\qquad \begin{array}{llllllllll}1 & 2 & 3 & 4 & 5 & 6 & 7 & 8 & 9 & 10\end{array}\end{array}$ \\
\hline $\begin{array}{l}\text { Child's focus during reading } \\
\qquad \begin{array}{llllllllll}1 & 2 & 3 & 4 & 5 & 6 & 7 & 8 & 9 & 10\end{array}\end{array}$ & $\begin{array}{l}\text { Child's focus during reading } \\
\qquad \begin{array}{llllllllll}1 & 2 & 3 & 4 & 5 & 6 & 7 & 8 & 9 & 10\end{array}\end{array}$ \\
\hline Comments: & Comments: \\
\hline
\end{tabular}


JoMR Fall 2017

Volume 3 (2)
THE EFFECTS OF CHOICE ON READING ENGAGEMENT

Fraumeni-McBride

Appendix D:

Sample reading quiz

Book title: A Cold Day

1. The story is mostly about...
A. a snowstorm.
B. cold weather.

2. What does the boy do after he feels the tree?
A. He feels the fence.
B. He feels the car.

3. Which of the following words tells the setting?
A. today
B. feels

4. How does the tree feel?
A. warm
B. cold

5. Listen to this sentence: The door handle is cold. What is another word for handle?
A. knob
B. window 
JoMR Fall 2017

Volume 3 (2)
THE EFFECTS OF CHOICE ON READING ENGAGEMENT

Fraumeni-McBride

Appendix E:

Descriptions of measures used in figures

RO1: Researcher Observation 1

Researcher-recorded perception of child’s interest level (10-point scale)

RO2: Researcher Observation 2

Researcher-recorded perception of child's enjoyment level (10-point scale)

RO3: Researcher Observation 3

Researcher-recorded perception of child's comprehension level (10-point scale)

RO4: Researcher Observation 4

Researcher-recorded perception of child's focus during reading (10-point scale)

SA1: Self-Assessment 1

Child self-assessed statement: I enjoy reading. (5-point scale)

SA2: Self-Assessment 2

Child self-assessed statement: I enjoy reading aloud. (5-point scale)

SA3: Self-Assessment 3

Child self-assessed statement: I enjoy reading silently. (5-point scale)

SA4: Self-Assessment 4

Child self-assessed statement: It's hard for me to understand what is going on when I read. (5point scale)

SA5: Self-Assessment 5

Child self-assessed statement: I am interested in the books that I am assigned to read. (5-point scale)

SA6: Self-Assessment 6

Child self-assessed statement: I can read well. (5-point scale)

SA7: Self-Assessment 7

Child self-assessed statement: I enjoy going to school. (5-point scale)

Q/C: Questions and Comments

Number of questions or comments made before, during, and after reading. 